\title{
Diffusion Coatings for Corrosion-Resistant Components in Coal Gasification Systems
}

Quarterly Technical Progress Report 8

Covering the period April 1, 2005 through June 30, 2005

SRI Project P13063

Contract No. DE-FC26-03NT41616

Prepared by:

Gopala N. Krishnan, Ripudaman Malhotra, Esperanza Alvarez, Kai-Hung Lau, and Angel Sanjurjo

SRI International

333 Ravenswood Avenue

Menlo Park, CA 94025

Prepared for:

U.S. Department of Energy

National Energy Technology Center

P. O. Box 10940

Pittsburgh, PA 15236

Attention: Dr. Richard Read 


\section{DISCLAIMER}

This report was prepared as an account of work sponsored by an agency of the United States Government. Neither the United States Government nor any agency thereof, nor any of their employees, makes any warranty, express or implied, or assumes any legal liability or responsibility for the accuracy, completeness, or usefulness of any information, apparatus, product, or process disclosed, or represents that its use would not infringe privately owned rights. Reference herein to any specific commercial product, process, or service by trade name, trademark, manufacturer, or otherwise does not necessarily constitute or imply endorsement, recommendation, or favoring by the United States Government or any agency thereof. The views and opinions of authors expressed herein do not necessarily state or reflect those of the United States Government or any agency thereof. 


\begin{abstract}
Heat exchangers, particle filters, turbines, and other components in an integrated coal gasification combined cycle system must withstand the highly sulfiding conditions of the hightemperature coal gas over an extended period of time. The performance of components degrades significantly with time unless expensive high-alloy materials are used. Deposition of a suitable coating on a low-cost alloy may improve its resistance to such sulfidation attack, and decrease capital and operating costs. The alloys used in the gasifier service include austenitic and ferritic stainless steels, nickel-chromium-iron alloys, and expensive nickel-cobalt alloys.

During this reporting period, we conducted a simulated gasifier test primarily with TiNcoated steel samples. Although the test showed these coatings to offer significant protection against corrosion, they also revealed a lack of uniformity in the coatings. We spent a considerable amount of effort improving our coatings procedure as well as the fluidized bed reactor and its heater. Based on the results collected thus far, we selected 12 samples and sent them to ConocoPhillips for testing in their gasifier at the Wabash River Energy plant.
\end{abstract}




\section{TABLE OF CONTENTS}

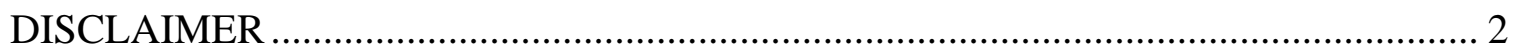

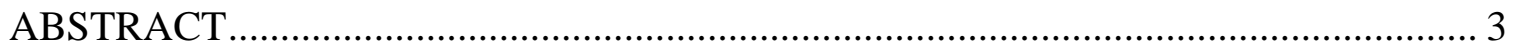

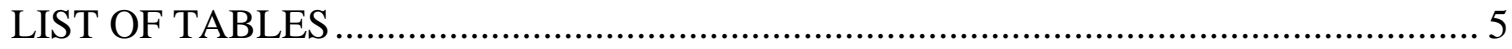

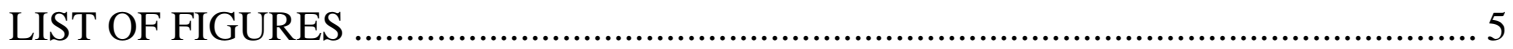

EXECUTIVE SUMMARY .............................................................................. 6

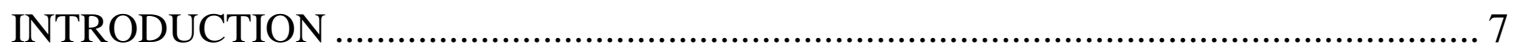

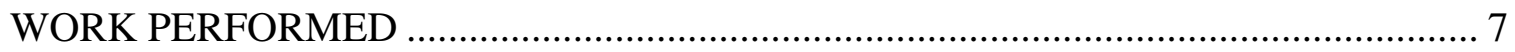

Exposure to Simulated Coal Gas: Test 7 .......................................................8

Improvements to the Coating Procedure .........................................................10

Samples for Exposure in ConocoPhillips Gasifier.............................................11

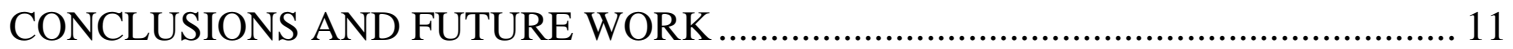




\section{LIST OF TABLES}

1. Samples Tested and Results Test 7a, 96 h (April 21, 2005) ..................................... 8

2. Samples Tested and Results Test 7b, 240 h (April 27, 2005) .................................... 9

3. Samples for Gasifier Exposure Tests (April 29, 2005)........................................... 12

\section{LIST OF FIGURES}

1. Samples from Exposure Test 7a, before and after exposure to simulated gasifier

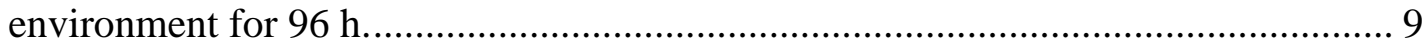

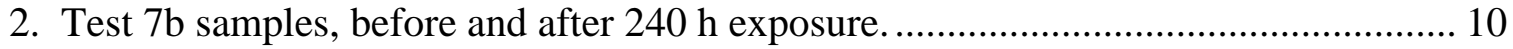




\section{EXECUTIVE SUMMARY}

Advanced coal gasification systems such as integrated coal gasification combined cycle (IGCC) processes offer many advantages over conventional pulverized coal combustors. Heat exchangers, filters, turbines, and other components in IGCC plants often must withstand the highly sulfiding conditions at high temperatures. In collaboration with U.S. Department of Energy and ConocoPhillips, we are developing corrosion-resistant coatings for high-temperature components in IGCC systems.

SG Solution's coal gasification power plant in Terre Haute, IN, uses ConocoPhillips' E-Gas technology. The need for corrosion-resistant coatings exists in two areas: (1) the tube sheet of a heat exchanger at $\sim 1000^{\circ} \mathrm{C}$ that is immediately downstream of the gasifier, and (2) porous metal particulate filter at $370^{\circ} \mathrm{C}$, which is downstream of the heat exchanger. These components operate at gas streams containing as much as $2 \% \mathrm{H}_{2} \mathrm{~S}$. A protective metal or ceramic coating that can resist sulfidation corrosion will extend the life-time of these components and reduce maintenance.

During this reporting period, we conducted a simulated gasifier test primarily with TiNcoated steel samples. Although the testing showed that these coatings offered significant protection against corrosion, it also revealed a lack of uniformity in the coatings. We spent a considerable amount of effort improving our coatings procedure, as well as the fluidized bed reactor and its heater. Based on the results collected thus far, we selected 12 samples and sent them to ConocoPhillips for testing in their gasifier at the Wabash River Energy plant. 


\section{INTRODUCTION}

Heat exchangers, filters, turbines, and other components in coal-fired power plants must withstand demanding conditions of high temperatures and pressure differentials. Further, the components are exposed to corrosive gases and particulates that can erode the material and degrade their performance. In collaboration with U.S. Department of Energy and ConocoPhillips, SRI International recently embarked on a project to develop corrosion-resistant coatings for coal-fired power plant applications. Specifically, we are seeking to develop coatings that would prevent the corrosion in the tube-sheet of the high-temperature heat recovery unit of a coal gasification power plant at SG Solution's facility in Terre Haute, IN, which uses ConocoPhillips' E-Gas technology. This corrosion is the leading cause of the unscheduled downtime at the plant and, hence, success in this project will directly impact the plant availability and its operating costs. Coatings that are successfully developed for this application will find use in similar situations in other coal-fired power plants.

\section{WORK PERFORMED}

During this reporting period, we conducted a simulated gasifier test primarily with TiNcoated steel samples. Although the test showed these coatings to offer significant protection against corrosion, they also revealed a lack of uniformity in the coatings. We spent a considerable amount of effort improving our coatings procedure, as well as the fluidized bed reactor and its heater. Based on the results collected thus far, we selected 12 samples and sent them to ConocoPhillips for testing in their gasifier at the Wabash River Energy plant.

A review of the literature showed that addition of $\mathrm{Ti}$ and $\mathrm{Si}$ to the alloy steels can be beneficial in improving their sulfidation resistance. 1 Formation of a compact, protective oxide layer that resists the ingress of $\mathrm{S}$ into the alloy is likely to be the cause of the improved sulfidation resistance. The Ni-Co-based alloy HR-160 contains Si as an additive and it has high sulfidation resistance. TiN coatings are used in the semiconductor resistance as diffusion barrier coatings. Based on these factors, we decided to investigate the use of TiN coatings.

1 K. Natesan, “Corrosion Resistance of Iron Aluminides.” Report by Argonne National Laboratory under Contract No. W31-109-Eng-38, 2001. 


\section{EXPOSURE TO SIMULATED COAL GAS: TEST 7}

The samples used in Test 7 and the results of exposure are listed in Table 1. We focused on samples coated with Ti nitride from several deposition runs with an attempt to get uniform coatings. To see the effect of surface morphology, we sand-blasted a sample of SS409 coupon (\#14) and coated it alongside another coupon that was not sand-blasted (\#14). Also included was a porous SS316 sample coated with (Ti/Ta) nitride to see if this coating would fare better than the previous attempts with Ti/T nitride (Exposure Test 4) or the oxidized Cr/Al-Al coating (Exposure Test 6). Figure 1 shows the picture of the coated samples before they were exposed to simulated gasifier conditions at $900^{\circ} \mathrm{C}$. The test was conducted for $96 \mathrm{~h}$, after which the reactive gases were turned off and the furnace cooled to retrieve the samples for examination. Figure 2 is a photograph of the samples after exposure.

Table 1. Samples Tested and Results Test 7a, 96 h (April 21, 2005)

\begin{tabular}{|c|l|l|l|}
\hline $\begin{array}{c}\text { Sample } \\
\text { No. }\end{array}$ & \multicolumn{1}{|c|}{ Material } & Coating/ Run & \multicolumn{1}{c|}{ Appearance } \\
\hline 1 & HR160 -08 & TiN/64 & Some discoloration \\
\hline 2 & Porous SS 360 & (Ti/Ta)N/62 & Badly corroded \\
\hline 3 & SS410 - 06 & TiN/65 & Pinhole corrosion or bubbles from adjacent sample \\
\hline 4 & SS409 - 12 & Ox-Cr/Al-Al/ 59 & No apparent degradation \\
\hline 5 & SS409 - 13 & TiN/63 & Some corrosion, reverse side looks good \\
\hline 6 & SS409 -14 & TiN/63 & Some corrosion, reverse side looks good \\
\hline
\end{tabular}



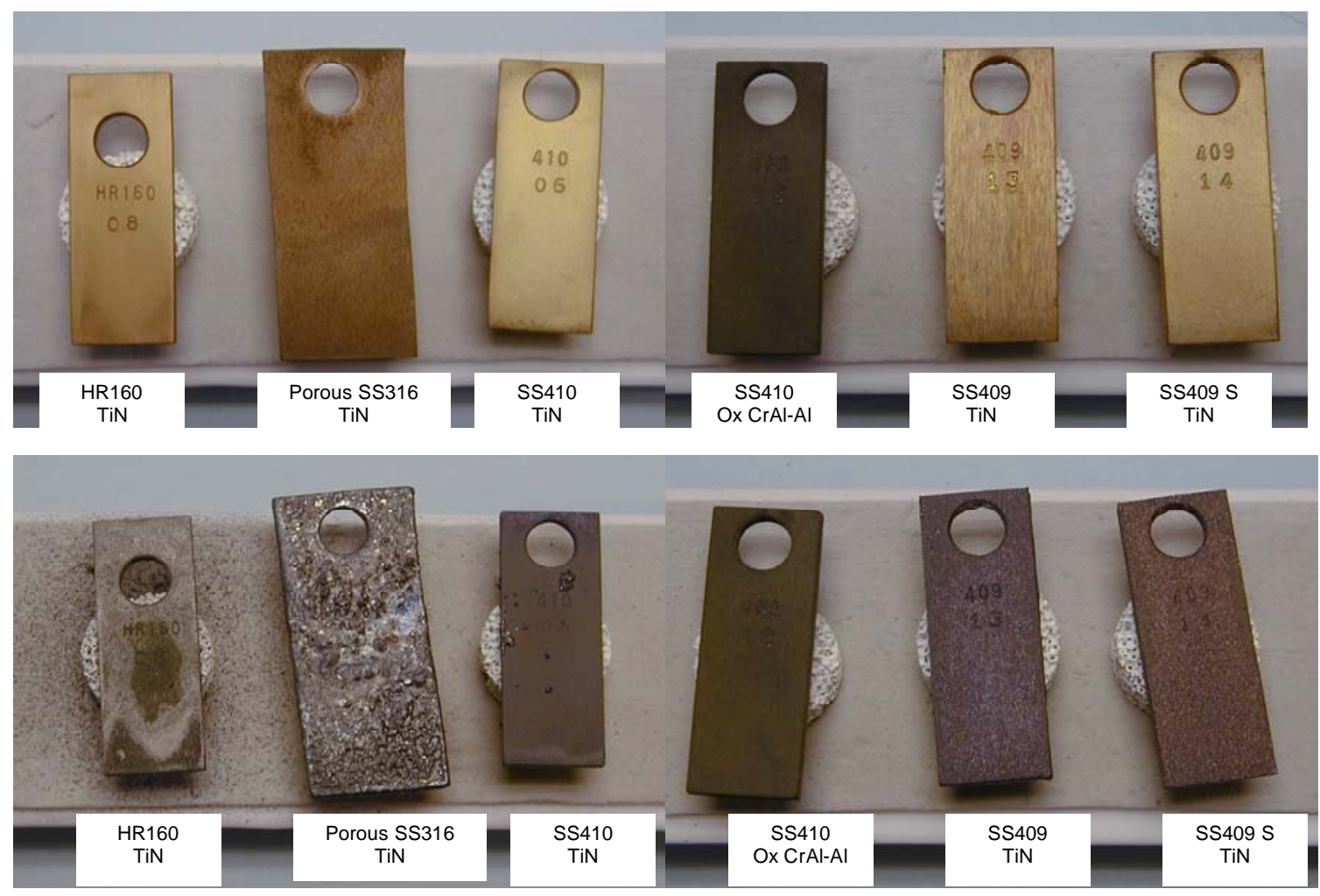

Figure 1. Samples from Exposure Test $7 \mathrm{a}$ before and after exposure to simulated gasifier environment for $96 \mathrm{~h}$.

We noticed that some of the samples in the run had different degrees of corrosion on the top and bottom surfaces although most of them seemed to have survived well. We decided to continue exposing them to gasification environment after flipping them over. Also, we removed the SS409-12 sample (coated with $\mathrm{Cr} / \mathrm{Al}$-Al, oxidized) that had survived over $500 \mathrm{~h}$ under the gasifier conditions with no signs of corrosion. We added a sample of TiN-coated SS405 that was recently prepared (run 66). Table 2 lists the samples that were exposed in the continuation of this run (Test 7b).

Table 2. Samples Tested and Results Test 7b, $240 \mathrm{~h}$ (April 27, 2005)

\begin{tabular}{|c|c|c|l|}
\hline $\begin{array}{c}\text { Sample } \\
\text { No. }\end{array}$ & Material & Coating/ Run & \multicolumn{1}{c|}{ Appearance } \\
\hline 1 & HR160 -08 & TiN/64 & Survived. Minimal corrosion at edges. \\
\hline 2 & SS409 -13 & TiN/63 & Lots of signs of corrosion. \\
\hline 3 & SS409 -14 & TiN/63 & Only edges corroded. \\
\hline 4 & SS410 -06 & TiN/65 & Only edges show corrosion. \\
\hline 5 & SS405 -17 & TiN/66 & Badly corroded. \\
\hline
\end{tabular}


By and large, these samples seemed to have fared well. The HR160 sample had minimal corrosion. The pair of SS409 samples show the effect of sand-blasting. The fact that corrosion was often limited to the edges and that sand-blasting also helped suggests that morphological stresses may be a contributing factor in corrosion. The SS405 sample showed extensive signs of corrosion. We have previously noted that the presence of $\mathrm{Ni}$ in the alloys such as the 300 series steels interferes with the formation of the diffusion barrier coating. The result with SS405 suggests that the presence of carbon in the alloy also interferes with the coating process. Only 409 steel, which has extremely low carbon, appears to be amenable to protection by our coating process.
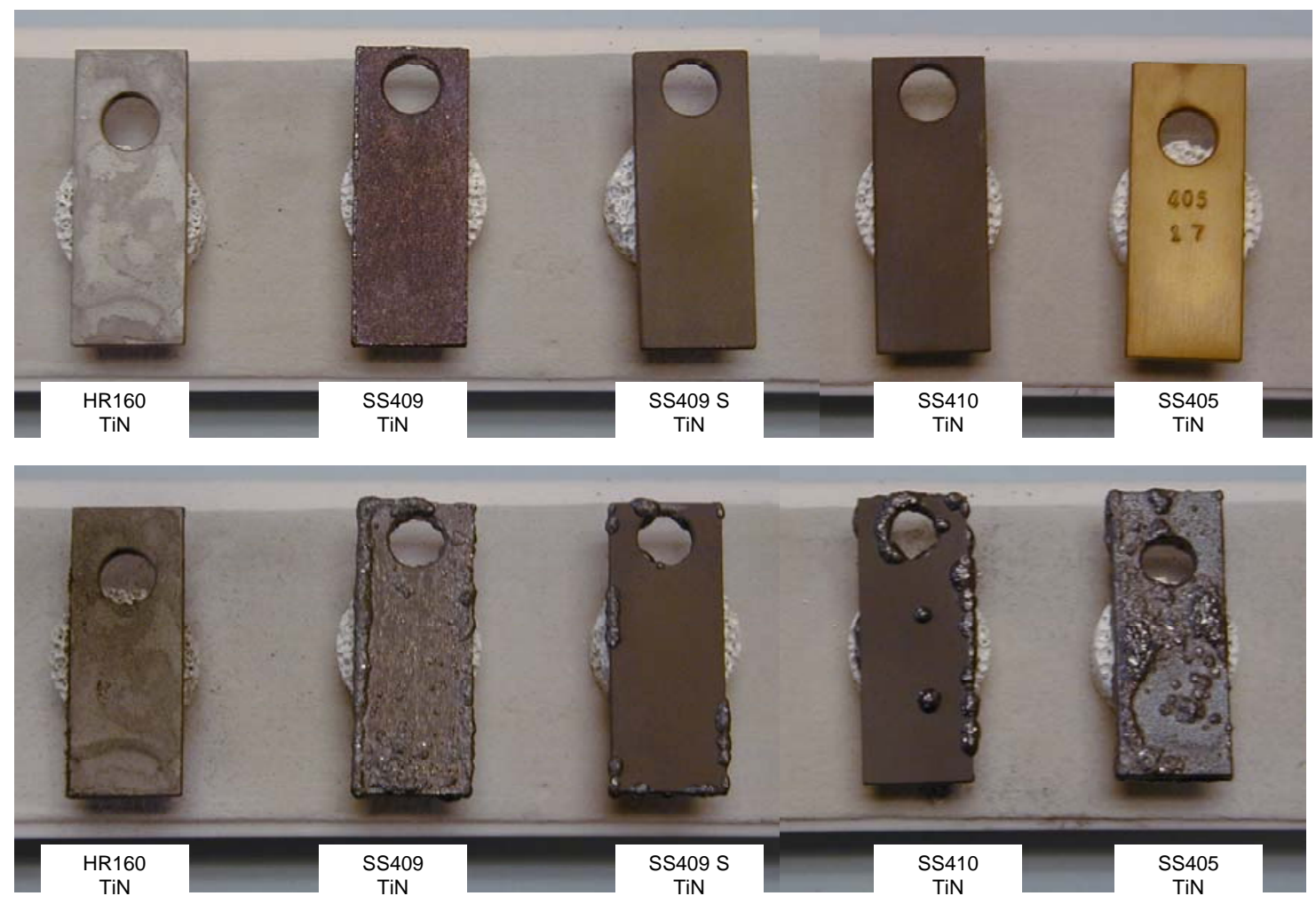

Figure 2. Test $7 \mathrm{~b}$ samples, before and after $240 \mathrm{~h}$ exposure.

\section{IMPROVEMENTS TO THE COATING PROCEDURE}

Fluidized beds generally provide uniform heat and mass transfer and, hence, we chose it for the coating step with the expectation that the coatings would be uniform. However, we observed that many of the coupons showed non-uniform coatings. Careful examination of the apparatus showed two major shortcomings. First, when we use many coupons in the same run, the fluidizing between the coupons is sometimes adversely affected. Second, portions of some of 
the coupons were outside the optimal heating zone of the RF heater. This Quarter, we began to address these deficiencies. We decided to use fewer coupons in the future runs and also increase the spacing between them. We also modified the heater coil to ensure that the coupons were completely within the RF heating zone. Details of the final coating procedure and surface analysis of the coated samples are presented in the next Quarterly Report.

\section{SAMPLES FOR EXPOSURE IN CONOCO PHILLIPS GASIFIER}

We had previously (June 2004) sent samples to ConocoPhillips for placement in their gasifier. However, because of certain difficulties with the run, the samples were never exposed to coal gas. Those samples were exposed to about $100 \mathrm{~h}$ of start-up attempts with natural gas.

Subsequent plant shutdown and labor disputes delayed the start of the next run. In July 2005, the plant was to be restarted, and that presented another opportunity to test samples in a real gasifier. Over the past year, we had improved our coating procedures and also observed that oxidized $\mathrm{Cr} / \mathrm{Al}-\mathrm{Al}$ and TiN coatings seemed to be quite effective. We chose samples of coated and uncoated alloys (listed in Table 2) for the test, and sent them to ConocoPhillips. These samples will likely be retrieved when the plant is next shut down for scheduled maintenance.

\section{CONCLUSIONS AND FUTURE WORK}

Both TiN and oxidized $\mathrm{Cr} / \mathrm{Al}-\mathrm{Al}$ coatings seem to offer protection against corrosion when the substrate does not contain Ni or carbon. We noticed that surface roughness impairs the quality of coating, and that sand blasting the sample prior to coating leads to better results. We also observed that the protection is least effective at the edges. These two observations may be linked, and point to some geometric factors that may cause a variation in local temperature. 
Table 3. Samples for Gasifier Exposure Tests (April 29, 2005)

\begin{tabular}{|c|c|c|c|c|l|}
\hline Coupon & Alloy & Marking & Coating & RUN NO. & \multicolumn{1}{|c|}{ Size (mm) } \\
\hline 1 & HR160 & 05 & None & - & $41.7 \times 19.6 \times 3.2$ \\
\hline 2 & I 800 & 08 & None & - & $51.2 \times 19.4 \times 3.7$ \\
\hline 3 & SS 410 & 05 & None & - & $51.2 \times 19.6 \times 3.0$ \\
\hline 4 & SS 304 L & 02 & None & - & $51.2 \times 19.5 \times 3.0$ \\
\hline 5 & SS 409 & 12 & Cr-Al/Al/Ox & 59 & $51.5 \times 19.5 \times 3.9$ \\
\hline 6 & SS 409 & 16 & Cr-Al/AI/Ox & 70 & $51.3 \times 19.5 \times 3.8$ \\
\hline 7 & SS 409 & 17 & Cr-Al/Al/Ox & 70 & $51.4 \times 19.5 \times 3.8$ \\
\hline 8 & SS 405 & 15 & TiN & 66 & $51.2 \times 19.6 \times 3.6$ \\
\hline 9 & SS 405 & 16 & TiN & 66 & $51.2 \times 19.5 \times 3.4$ \\
\hline 10 & SS 409 & 18 & TiN & 68 & $51.5 \times 19.5 \times 3.8$ \\
\hline 11 & SS 409 & 20 & TiN & 68 & $51.4 \times 19.5 \times 3.9$ \\
\hline 12 & SS 316 & - & TiN & 62 & $52.8 \times 24.8 \times 3.3$ \\
\hline
\end{tabular}

1. Sample 5 has already survived $500+$ hours in simulated gasifier environment in the lab.

2. Sample 12 will not survive the high-temperature conditions. It is to be exposed to only colder gases after the HTRU, perhaps in a slip stream. 